\title{
Chronic transformation of muscle in spasticity: a peripheral contribution to increased tone
}

\author{
A HUFSCHMIDT, K-H MAURITZ
}

SUMMARY Mechanical properties of relaxed lower leg muscles were assessed by torque measurements during imposed constant velocity dorsiflexion-plantarflexion cycles. At low angular velocities, they exhibited an elastic and an energy-consuming, velocity-independent (plastic) resistance. In most patients with long-standing spasticity, both of these were enhanced. The results support the hypothesis of secondary structural changes of muscles in spasticity.

Spastic increase of muscle tone is estimated by the resistance to passive movements in a patient instructed to "let go". It is considered to be due to enhanced stretch reflexes. Recent findings, however, indicate that the increase in tone is not sufficiently accounted for by this mechanism. The EMG activity in the gastrocnemius muscle when stretched during the stance and swing phase is rather low relative to an excessive activation of the tibialis anterior. ${ }^{2}$ It is concluded from this finding that the tibialis anterior has to overcome a resistance of non-reflex origin, probably owing to an alteration of passive mechanical properties of the triceps surae muscle. Evidence for an alteration in viscoelastic behaviour of muscles in severe spasticity has been reported previously. ${ }^{3}$

This study was undertaken to define the passive mechanical properties of spastic muscle in terms of elastic, viscous or plastic resistance to stretch. This was done by calculation of the work absorbed in cycles of passive movements at constant velocities. The results indicate that elastic and velocityindependent plastic resistance are enhanced in long-standing spasticity and support the hypothesis of secondary tonic transformation of muscles as an additional component of increased muscle tone. A preliminary account of this work has been published. ${ }^{4}$

\section{Subjects and methods}

Subjects

Experiments were performed on 20 healthy (M:F = 15:5;

Address for reprint requests: Dr A Hufschmidt, Abt. Klinische Neurologie and Neurophysiologie, Haastr. 9, D-7800 Freiburg i, Brsg, Fed Rep Germany.

Received 15 June 1984 and in revised form 6 November 1984. Accepted 17 November 1984 mean age $43.1 \pm 15.4$ years) and 21 spastic individuals (M:F $=18: 3$; mean age $54 \cdot 3 \pm 13 \cdot 1$ years), who gave their informed consent to the experiments including ischaemic blockade (one patient). The control group included the unaffected legs of 10 hemispastic patients (carefully selected for the absence of any history or clinical signs of bilateral neurological deficit) to obtain better age matching. The classification of those legs as "normal" is based on clinical criteria and does not take into account the known electrophysiological abnormalities on the non-affectedside of some hemispastic patients. The patient group consisted of 10 hemispastic (4 right, 6 left) and 11 para- or tetraspastic subjects. Some patients had sensory symptoms or slight ataxia due to spinal cord or cerebral disease, but patients with peripheral neurological deficit in the leg to be examined were excluded from the study. Most of our patients with long-standing spasticity, when examined clinically, were found to have slight to moderate contractures of the calf muscles. In all of them, however, a $10^{\circ}$ dorsiflexion was within the range of passive movement without inducing discomfort. The patients' subjective reports on the onset of spastic symptoms were checked with clinical notes, if accessible. Patient data are summarised in Table 1.

\section{Experimental procedure}

One foot was fixed to a pedal driven by a servo-motor about an axis aligned with the ankle. The resisting torque developed by the foot was measured by strain gauges registering the elastic deformation of the pedal along a breaking-line. The pedal position was monitored by a potentiometer connected to its axis. This signal was also used for position feedback control. The surface EMGs of the tibialis anterior, gastrocnemius and, in some experiments, soleus muscle were recorded by conventional techniques. Position and force signals as well as EMG were stored on tape (Bell \& Howell VR 3200 FM tape recorder) and averaged by a Nicolet 1070 averager operating on four channels with a resolution of 256 points per channel. EMG signals were full-wave rectified before averaging. At the beginning of each trial a short interval preceding the onset of pedal movement was recorded as a force baseline. 
Table 1 Patient data.

\begin{tabular}{|c|c|c|c|c|c|c|c|c|}
\hline $\begin{array}{l}\text { Exp } \\
\text { No }\end{array}$ & $\begin{array}{l}\text { Age } \\
(y r)\end{array}$ & Sex & Diagnosis & $\begin{array}{l}\text { Duration of } \\
\text { illness }\end{array}$ & Paresis & Ankle jerk & $\begin{array}{l}\text { Plantar } \\
\text { response }\end{array}$ & Ankle clonus \\
\hline $\begin{array}{l}32 \\
37 \\
45 \\
48 \\
51 \\
53\end{array}$ & $\begin{array}{l}48 \\
37 \\
51 \\
71 \\
48 \\
62\end{array}$ & $\begin{array}{l}\mathbf{F} \\
\mathbf{M} \\
\mathbf{F} \\
\mathbf{M} \\
\mathbf{M} \\
\mathbf{F}\end{array}$ & $\begin{array}{l}\text { R CVA } \\
\text { MS } \\
\text { MS } \\
\text { R CVA } \\
\text { MS } \\
\text { hereditary spastic } \\
\text { paraplegia }\end{array}$ & $\begin{array}{r}14 \mathrm{~m} \\
6 \mathrm{w} \\
4 \mathrm{y} \\
3 \mathrm{y} \\
8 \mathrm{~m} \\
20 \mathrm{y}\end{array}$ & $\begin{array}{l}++ \\
(+) \\
+++ \\
+ \\
+ \\
++\end{array}$ & $\begin{array}{l}+++ \\
++ \\
+++ \\
+++ \\
+++ \\
+++\end{array}$ & $\underset{\uparrow}{\uparrow}$ & $\begin{array}{l}+ \\
+ \\
+ \\
+ \\
+\end{array}$ \\
\hline $\begin{array}{l}55 \\
60 \\
65\end{array}$ & $\begin{array}{l}43 \\
26 \\
43\end{array}$ & $\begin{array}{l}\mathbf{M} \\
\mathbf{M} \\
\mathbf{M}\end{array}$ & $\begin{array}{l}\text { L glioma } \\
\text { MS } \\
\text { spastic tetraparesis, } \\
\text { unknown aetiology }\end{array}$ & $\begin{array}{l}4.5 \mathrm{~m} \\
3.5 \mathrm{y} \\
6 \mathrm{y}\end{array}$ & $\begin{array}{l}++ \\
++ \\
+\end{array}$ & $\begin{array}{l}+++ \\
+++ \\
+++\end{array}$ & $\stackrel{\uparrow}{\uparrow}$ & $\begin{array}{l}+ \\
+ \\
+\end{array}$ \\
\hline $\begin{array}{l}69 \\
70\end{array}$ & $\begin{array}{l}62 \\
72\end{array}$ & $\begin{array}{l}\mathbf{M} \\
\mathbf{M}\end{array}$ & $\begin{array}{l}\text { R CVA } \\
\text { cervical } \\
\text { myelopathy }\end{array}$ & $\begin{array}{l}2 \mathrm{y} \\
2 \mathrm{y}\end{array}$ & $\begin{array}{l}(+) \\
++\end{array}$ & $\begin{array}{l}++ \\
++\end{array}$ & $\uparrow$ & $\overline{+}$ \\
\hline 73 & 71 & $\mathbf{M}$ & $\begin{array}{l}\text { mervical } \\
\text { myelopathy }\end{array}$ & $22 y$ & ++ & +++ & $\downarrow$ & - \\
\hline $\begin{array}{l}75 \\
76\end{array}$ & $\begin{array}{l}67 \\
46\end{array}$ & $\begin{array}{l}\mathbf{M} \\
\mathbf{M}\end{array}$ & $\begin{array}{l}\text { R CVA } \\
\text { spastic hemiparesis, } \\
\text { unknown aetiology }\end{array}$ & $\begin{array}{l}6 y \\
4 y\end{array}$ & $\begin{array}{l}++ \\
(+)\end{array}$ & $\begin{array}{l}+++ \\
+++\end{array}$ & $\uparrow$ & $\bar{t}$ \\
\hline $\begin{array}{l}77 \\
81\end{array}$ & $\begin{array}{l}74 \\
59\end{array}$ & $\begin{array}{l}\mathbf{M} \\
\mathbf{M}\end{array}$ & $\begin{array}{l}\text { L glioma } \\
\text { hereditary spastic } \\
\text { paraplegia }\end{array}$ & $\begin{array}{l}7 \mathrm{~m} \\
6 \mathrm{~m}\end{array}$ & $\stackrel{+}{(+)}$ & $\begin{array}{l}+++ \\
+++\end{array}$ & $\uparrow$ & $\overline{+}$ \\
\hline $\begin{array}{r}86 \\
87 \\
108 \\
125 \\
126\end{array}$ & $\begin{array}{l}56 \\
39 \\
50 \\
61 \\
53\end{array}$ & $\begin{array}{l}\mathbf{M} \\
\mathbf{M} \\
\mathbf{M} \\
\mathbf{M} \\
\mathbf{M}\end{array}$ & $\begin{array}{l}\text { MS } \\
\text { L CVA } \\
\text { R CVA } \\
\text { L CVA } \\
\text { MS }\end{array}$ & $\begin{array}{l}4 \mathrm{y} \\
2 \cdot 25 \mathrm{y} \\
2.5 \mathrm{y} \\
2 \cdot 5 \mathrm{~m} \\
4 \cdot 5 \mathrm{y}\end{array}$ & $\begin{array}{l}(+) \\
++ \\
+ \\
++ \\
++\end{array}$ & $\begin{array}{l}+++ \\
+++ \\
+++ \\
+++ \\
+++\end{array}$ & $\stackrel{\uparrow}{\uparrow}$ & $\begin{array}{l}+ \\
+ \\
+ \\
-\end{array}$ \\
\hline
\end{tabular}

Paraesis: $(+)=$ latent, $+=$ slight, $++=$ marked, $+++=$ unable to walk alone. CVA $=$ cerebrovascular accident.

MS $=$ multiple sclerosis

In most experiments, 16 trials were averaged. The minimum number of trials was four. Averaged curves of EMG, pedal position and force were plotted on an $x-$ $y$-plotter. The force recordings were integrated digitally by the averager. Mechanical responses were recorded for five rates of stretch: $2^{\circ}, 8^{\circ}, 20^{\circ}, 80^{\circ}$ and $200^{\circ}$ s. Subjects were seated comfortably in a chair with knees positioned approximately at a right angle. Surface electromyograms were displayed on a oscilloscope to provide the subject with visual feedback. For $2^{\circ}, 8^{\circ}$ and $20^{\circ} / \mathrm{s}$ stretches, trials during which EMG activity occurred were discarded. In this situation, all normal and most spastic subjects were able to relax so that no surface EMG could be observed in the recorded muscles. Preliminary tests showed a strong influence of pre-stretch ankle angle on elastic and plastic resistance. The initial angle was therefore maintained at $10^{\circ}$ plantarflexion, the edge of the tibia serving as a reference line for lower leg position. From here the pedal was moved through triangular-shaped dorsiflexionplantarflexion cycles of $20^{\circ}$ amplitude (fig 2B). Owing to inertial effects of the gearbox and pedal, the position curve at $80 \%$ was slightly splayed. At $200 \%$, therefore, trapezoid stimuli were applied with plateau duration ranging from 0.5 to $1.5 \mathrm{~s}$. With increasing intervals between stretch cycles, the force curve tended to develop a shoulder (fig 6A). In order to prevent this, the stimuli were applied in rapid sequence. For the same reason, the first trial of each series was discarded.

With this procedure the length-tension curves were precisely reproducible throughout the experimental session as demonstrated in fig 1 which shows superimposed curves of eight trials.

To assess the contribution of reflex activity to plastic

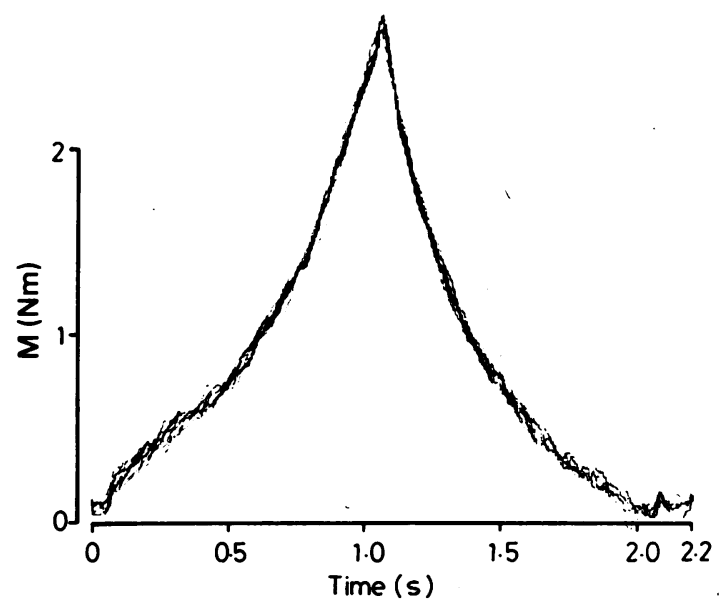

Fig 1 Superimposed tension curves of 8 successive trials in a normal subject.

resistance, ischaemic deafferentation was accomplished by cuffing the thigh at a pressure of $300 \mathrm{~mm} \mathrm{Hg} \mathrm{(40} \mathrm{kPa),} \mathrm{well}$ above arterial pressure. Large diameter Ia fibres are known to be easily blocked by ischaemia. ${ }^{5-7}$ Passive resistance to slow stretch as well as reflex responses to a test stimulus were assessed before and at 5 min intervals during ischaemia up to $30 \mathrm{~min}$. Test stimuli consisted of rapid $\left(140 \%\right.$ s) dorsiflexion pedal steps of $5^{\circ}$ amplitude delivered at frequencies of $0 \cdot 5-1 \mathrm{~Hz}$, which invariably evoked a stretch reflex response. 
(a)

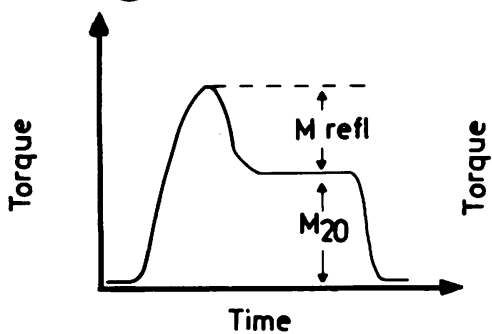

(b)

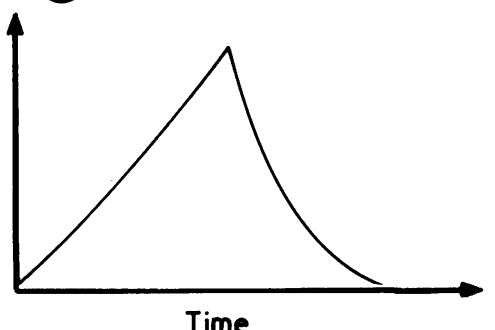

Time

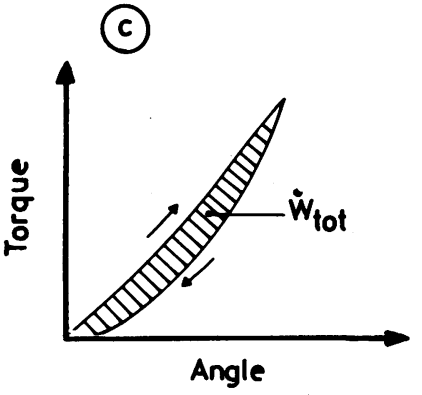

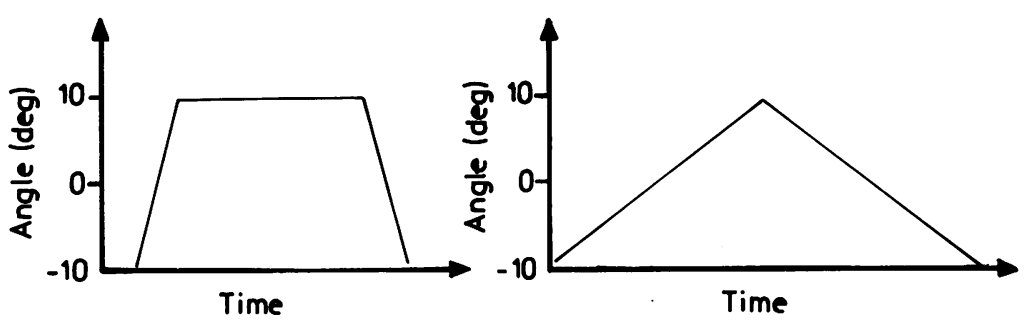

Fig 2 Graphic illustration of the parameters tested. Pedal movements are from $10^{\circ}$ plantarflexion $\left(-10^{\circ}\right)$ to $10^{\circ}$ dorsiflexion $\left(+10^{\circ}\right)$. Rapid dorsiflexion $(a)$ produces a reflex peak in the tension curve. The torque difference between $+10^{\circ}$ and $-10^{\circ}$ is termed $M_{2 \sigma}$ At velocities of $2^{\circ}, 8^{\circ}, 20^{\circ}$ and $80^{\circ} \%$ pedal movements are triangular (b). By plotting torque against angle, a hysteresis curve (c) is obtained. The energy absorbed by the muscle during one complete cycle is equivalent to the area encircled by the hysteresis loop $\left(W_{\text {tot }}\right)$.

\section{Parameters}

Since torque readings are dependent on the size of the foot, each subject's data were standardised using a correction factor which was related to the distance between the base of the 1st phalanx and the projection of the ankle axis on the pedal (lever length).

The following parameters were computed (fig 2):

(1) The force momentum with which the ankle resisted a $10^{\circ}$ dorsiflexion from a starting position of $10^{\circ}$ plantarflexion under static conditions was termed $\mathbf{M}_{20}$ (fig $2 \mathrm{~A}$ ). This parameter was calculated from a $200 \% \mathrm{~s}$ trapezoid stretch after decay of the initial reflex response $(1 \cdot 5 \mathrm{~s})$. The associated slow decay in tension during sustained stretch ${ }^{3}$ was disregarded in these experiments because it can be expected to be of little relevance at physiological rates of movement. $\mathbf{M}_{20}$ is a measure of the combined elastic stiffness of the muscles acting on the ankle, the influence of the antagonistic tibialis anterior entering with a negative sign.

(2) The maximum resistance generated by the reflex response to forced $20^{\circ}-200 \%$ s dorsiflexion $\left(M_{\text {refl }}\right)(f i g 2 A)$.

(3) The total energy, $W_{\text {tot }}$, expended by the apparatus to move the foot through a complete $20^{\circ}$ dorsiflexionplantarflexion cycle, graphically displayed by the area encircled by the hysteresis loop (fig $2 \mathrm{C}$ ), a parameter used by a number of other workers. ${ }^{8-12} \mathrm{~W}_{\text {tot }}$ reflects the energy consumed by both the triceps surae as well as the anterior tibial muscle and allows no distinction as to the relative contribution of the antagonistic muscles groups. It is affected by viscous and plastic forces resisting stretch but not by the elastic resistance because by definition the elastic energy absorbed during the dorsiflexion phase is regained during plantarflexion.

Both $M_{20}$ and $W_{\text {tot }}$ were found to correlate with the
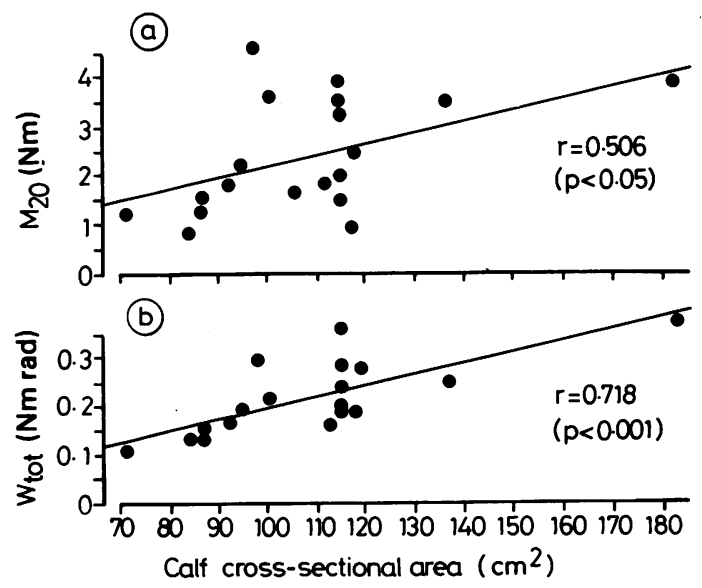

Fig 3 Correlation between $M_{20}$ and $W_{\text {tot }}$ at $2 \%$, respectively, and the maximum cross sectional area of the lower leg muscles in normal subjects. Both correlations are significant ( $a: r=0.506, p<0.05 ; b: r=0.718$, $p<0.01)$. 
maximum cross-sectional area of the calf (fig 3), which reflects the influence of muscle volume on its mechanical properties. To correct for individual differences, the maximum circumference of the calf was measured in each subject and its torque and work readings were standardised to a calf cross-sectional area of $97.5 \mathrm{~cm}^{2}$, corresponding to a calf circumference of $35 \mathrm{~cm}$.

\section{Results}

\section{Normal subjects}

In all subjects tested, energy $\left(\mathrm{W}_{\text {tot }}\right)$ was consumed by the lower leg muscles during the dorsiflexionplantarflexion cycles. Figure 4 shows the hysteresis loops of a normal subject. Mean values of $\mathrm{W}_{\text {tot }}$ at the five angular velocities tested are plotted in fig 5 . At $2^{\circ}, 8^{\circ}$ and $20^{\circ} / \mathrm{s}$ respectively, $\mathrm{W}_{\text {tot }}$ was found to be almost entirely independent of velocity. If anything, there was a slight (but non-significant) decrease with increasing angular velocity. No stretch reflexes were observed at these velocities, but at $80 \%$ s and $200 \%$ there was a steep increase in work absorption $\left(\mathrm{W}_{\text {tot }}\right)$ due to stretch reflex activity. Prolongation of the resting period between two successive stretch cycles to 1-2 s produced a shoulder (marked " $\downarrow$ " in fig 6A) in the dorsiflexion part of the length-tension curve. The force momentum represented by this shoulder was termed $\mathbf{M}_{\mathbf{S}}$. Its physiological significance will be discussed below. $M_{S}$ was found to be related to the duration of the resting interval (fig 6B) by a saturation curve, saturation of $M_{S}$ being reached at resting intervals of about $20 \mathrm{~s}$.

$\mathrm{W}_{\text {tot }}$ at slow angular velocities $\left(2^{\circ}-20^{\circ} / \mathrm{s}\right)$ was unaffected by ischaemic blockage of Ia afferents in the leg as shown in fig 7. In this experiment ankle jerks were elicited by rapid pedal movements $\left(140^{\circ} / \mathrm{s}\right)$ of $5^{\circ}$ amplitude. Twenty to 25 minutes after onset of

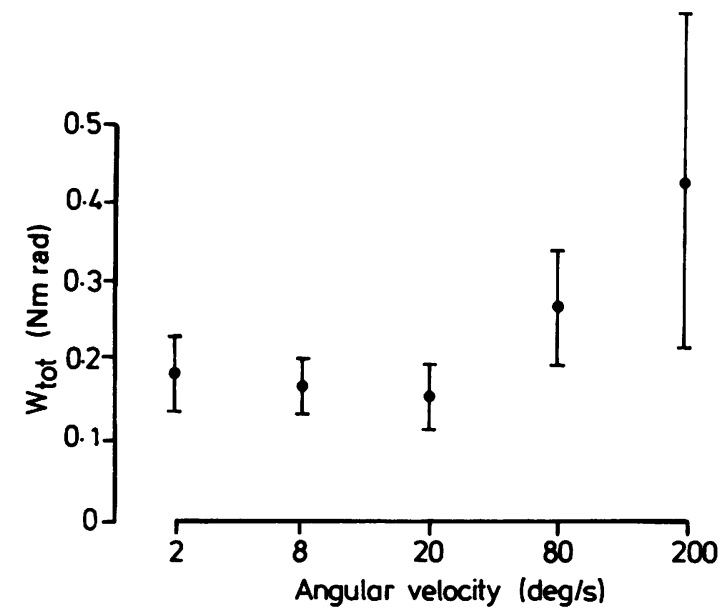

Fig 5 Mean values of $W_{\text {to }}$ in 20 normal subjects at the five angular velocities tested. $U_{p}^{t}$ to $20 \%$, there is an insignificant decrease of $W_{\text {tot }}$ in relation to angular velocity. The increase at $80^{\circ}$ and $200^{\circ} / \mathrm{s}$ is due to reflex activity.

ischaemia, stretch reflexes could no longer be obtained, while $\mathrm{W}_{\text {tot }}$ remained unchanged.

Mean values of $\mathrm{M}_{20}, \mathrm{M}_{\text {refl }}, \mathrm{W}_{\text {tot }}$ and $\mathrm{M}_{\mathrm{S}}$ are listed in table 2. Individual scatter of parameters, presumably due to differences of biomechanical conditions and reflex excitability, was considerable, with variation coefficients ranging from 21 to $104 \%\left(\mathrm{M}_{20}\right.$ : $44 \%, \mathrm{M}_{\mathrm{R}}: 104 \%, \mathrm{M}_{\mathrm{s}}: 26 \%, \mathrm{~W}_{\text {tot }}$ at $2^{\circ}$ to $80^{\circ} / \mathrm{s}: 22-$ $28 \%, \mathrm{~W}_{\text {tot }}$ at $200 \% \mathrm{~s}: 50 \%$ ).

\section{Spastic patients}

In all patients with less than a year's history of spastic symptoms (group 1), the elastic resistance to stretch under static conditions, as indicated by $\mathbf{M}_{20}$,

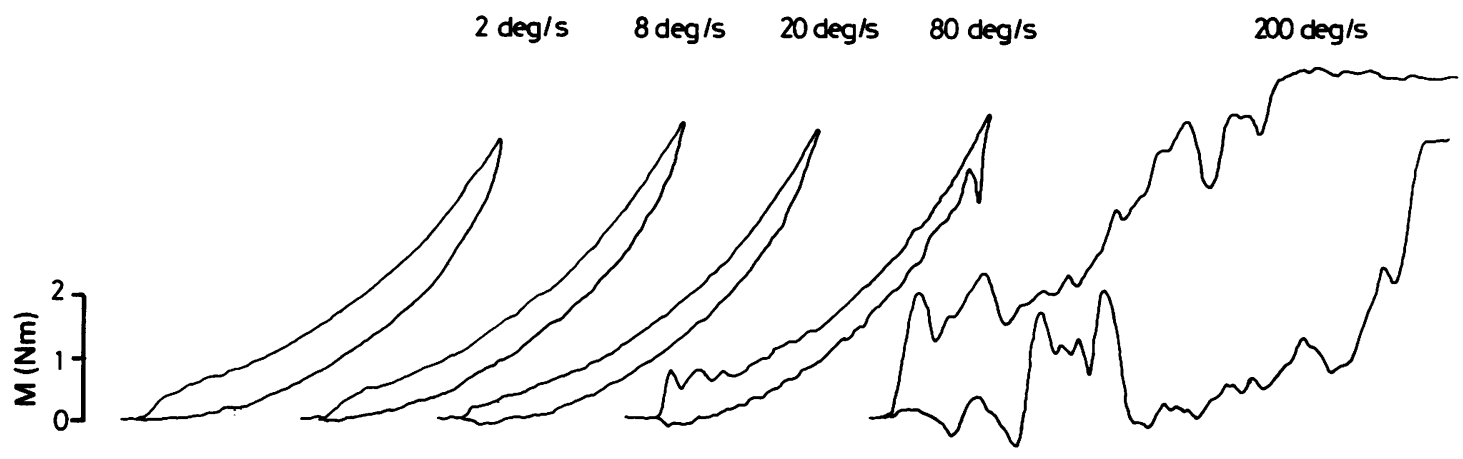

Fig 4 Length-tension curves of a normal subject at $2^{\circ}, 8^{\circ}, 20^{\circ}, 80^{\circ}$ and $200^{\circ} / \mathrm{s}$ (average of 16 trials). Increase of angular velocity by factor of 10 (from $2^{\circ}$ to $20^{\circ} / \mathrm{s}$ ) does not infuence the area encircled by the hysteresis loop, that is, the work absorbed by the calf muscles. At $80 \%$, the shape of the curve is changed by reflex activity as well as acceleration and deceleration peaks. 


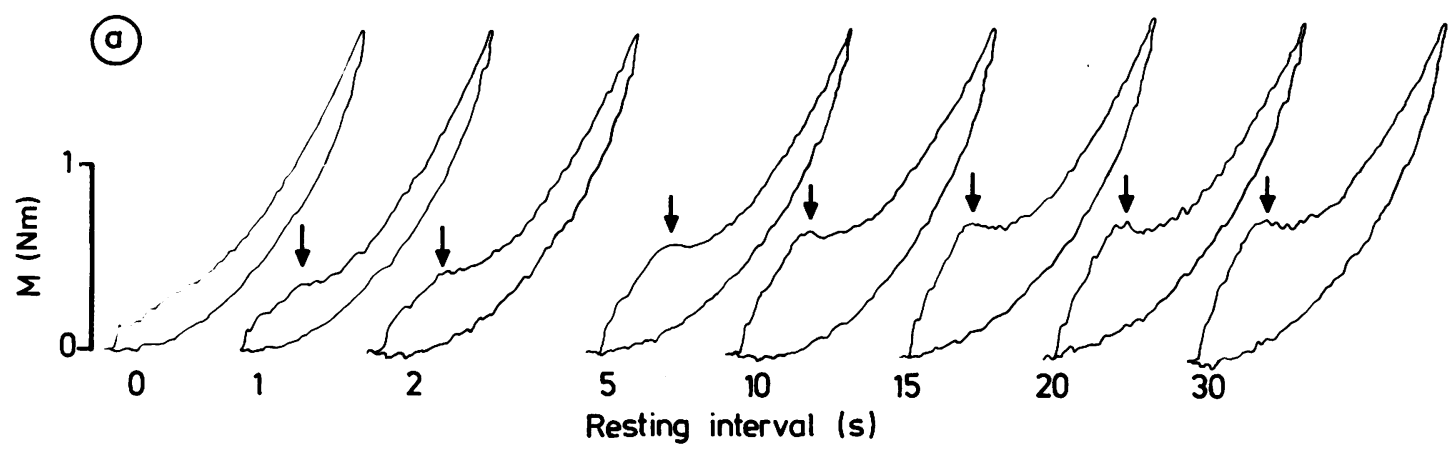

(b)
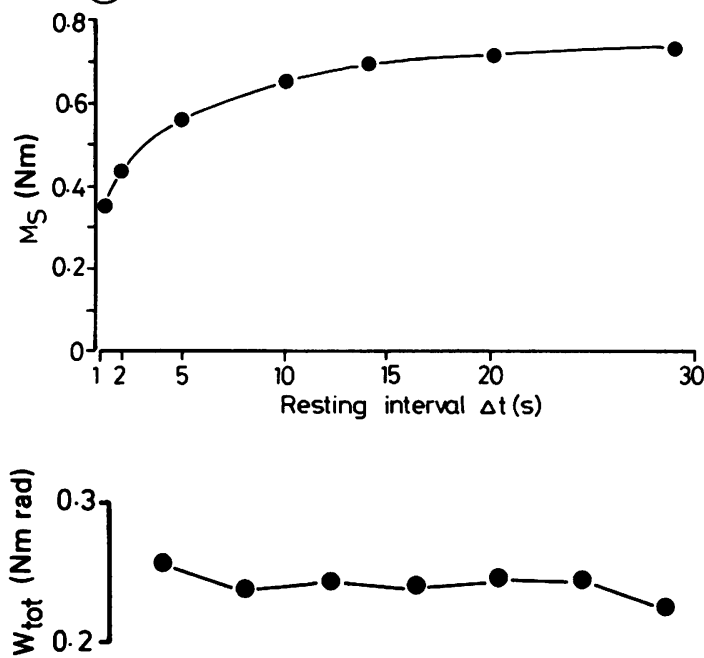

Integrated reflex octivity (test stimulus $140 \mathrm{deg} / \mathrm{s}$ ) Arbitrary units

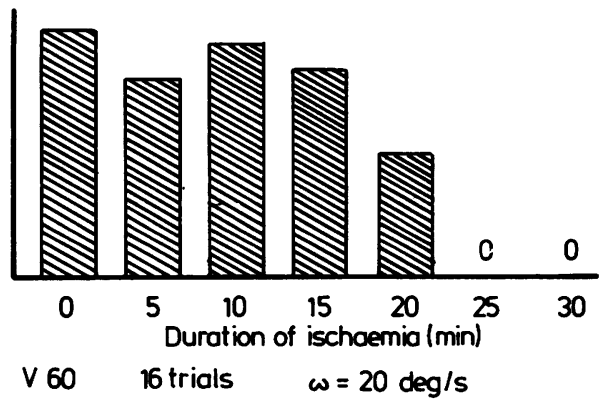

Fig 7 Work absorbed in the calf muscles $\left(W_{\text {tot }}\right)$ at $20 \% \mathrm{~s}$ passive stretch before and during pneumatic cuffing of the thigh at $300 \mathrm{~mm} \mathrm{Hg}(40 \mathrm{kPa})$. Spastic patient $(V 60)$. Lower half: Integrated gastrocneumius EMG activity (arbitrary units) in response to a test stimulus (forced $140 \%$ dorsiflexion). Blocking of Ia afferents is demonstrated by decrease of reflex amplitude. $W_{\text {tot }}$ is not dependent on the functioning of segmental reflexes.
Fig 6 (a) Length-tension curves $(20 \%)$ recorded at various intervals. Depending on the length of the resting period between stretch cycles, a "shoulder" ( $\downarrow$ ) appears in the L-T-curve. (b) Relation between $M_{20}$ and the resting interval between two successive stretches (one subject).

and the energy consumed by the muscles during one stretch cycle $\left(\mathrm{W}_{\text {tot }}\right)$ were in the normal range (fig 9A, B, C).

The mechanical reflex amplitude $\left(M_{R}\right)$ was increased in all but one of these patients (fig 9D). $\mathrm{W}_{\text {tot }}$ readings in the four hemispastic patients of this group were diminished by $5 \%$ to $45 \%$ on the spastic side as compared to the unaffected one (fig 9F).

In patients who had been suffering from spasticity for one year and longer (group 2), length-tension curves were mostly steeper than in normal subjects. Accordingly, the $\mathbf{M}_{20}$ parameter, as a measure of elastic resistance (triceps surae minus tibialis anterior muscle), was significantly elevated ( $p<$ 0.01 ) in these patients. The energy consumed by the ankle extensor and flexor muscles during one stretch cycle $\left(\mathrm{W}_{\text {tot }}\right)$ was also increased (fig 9A, B). The differences were most evident in hemiparetic patients owing to optimum matching of biomechanical factors between the two legs (fig 8,9F). One patient (V60) underwent ischaemic blocking of Ia afferents (fig 7). There was no significant change of $W_{\text {tot }}$ parallel to the reduction of ankle jerk amplitude. There was a significant correlation $(\mathrm{p}<1 \%)$ between the elastic resistance $\left(\mathrm{M}_{20}\right)$ and plastic resistance as represented by $\mathrm{W}_{\text {tot }}$ in the two groups of patients taken together (fig 10). Mean values of the results obtained in group 2 patients are listed in table 2. 
Table 2 Mean values of mechanical muscle parameters in normal subjects $(n=20)$ and patients with more than one year of spastic symptoms $(n=15)$

\begin{tabular}{|c|c|c|c|c|c|}
\hline & & & Normal subjects & $\begin{array}{l}\text { Spastic patients } \\
(>1 \text { y of spastic sy) }\end{array}$ & \\
\hline $\begin{array}{l}M_{20} \\
M_{R} \\
M_{S} \\
W_{\text {tot }} \\
W_{\text {tot }} \\
W_{\text {tot }} \\
W_{\text {tot }} \\
W_{\text {tot }} \\
W_{\text {dors }} \\
W_{\text {dors }} \\
W_{\text {dors }} \\
W_{\text {dors }} \\
W_{\text {dors }}\end{array}$ & $\begin{array}{r}2 \mathrm{deg} / \mathrm{s} \\
8 \mathrm{deg} / \mathrm{s} \\
20 \mathrm{deg} / \mathrm{s} \\
80 \mathrm{deg} / \mathrm{s} \\
200 \mathrm{deg} / \mathrm{s} \\
2 \mathrm{deg} / \mathrm{s} \\
8 \mathrm{deg} / \mathrm{s} \\
20 \mathrm{deg} / \mathrm{s} \\
80 \mathrm{deg} / \mathrm{s} \\
200 \mathrm{deg} / \mathrm{s}\end{array}$ & $\begin{array}{l}\text { (Nm) } \\
\text { (Nm) } \\
\text { (Nm) } \\
\text { (Nm rad) } \\
\text { (Nm rad) } \\
\text { (Nm rad) } \\
\text { (Nm rad) } \\
\text { (Nm rad) } \\
\text { (Nm rad) } \\
\text { (Nm rad) } \\
\text { (Nm rad) } \\
\text { (Nm rad) } \\
\text { (Nm rad) }\end{array}$ & $\begin{array}{l}2.20 \pm 0.96 \\
1.36 \pm 1.42 \\
0.76 \pm 0.19 \\
0.184 \pm 0.049 \\
0.168 \pm 0.035 \\
0.159 \pm 0.045 \\
0.268 \pm 0.076 \\
0.427 \pm 0.212 \\
0.360 \pm 0.129 \\
0.363 \pm 0.125 \\
0.352 \pm 0.120 \\
0.456 \pm 0.191 \\
0.554 \pm 0.240\end{array}$ & $\begin{array}{l}3.35 \pm 1.70 \\
4.30 \pm 4.29 \\
0.96 \pm 0.23 \\
0.251 \pm 0.060 \\
0.219 \pm 0.065 \\
0.221 \pm 0.091 \\
0.504 \pm 0.388 \\
0.983 \pm 0.686 \\
0.612 \pm 0.317 \\
0.567 \pm 0.222 \\
0.587 \pm 0.272 \\
1.202 \pm 1.155 \\
1.200 \pm 0.719\end{array}$ & $\begin{array}{l}++ \\
+++ \\
+ \\
++++ \\
+++ \\
++ \\
++ \\
++++ \\
+++ \\
++++ \\
++++ \\
+++ \\
++++\end{array}$ \\
\hline
\end{tabular}

Significance levels: $+=5 \%,++=1 \%,+++=0 \cdot 5 \%,++++=0.1 \%$.
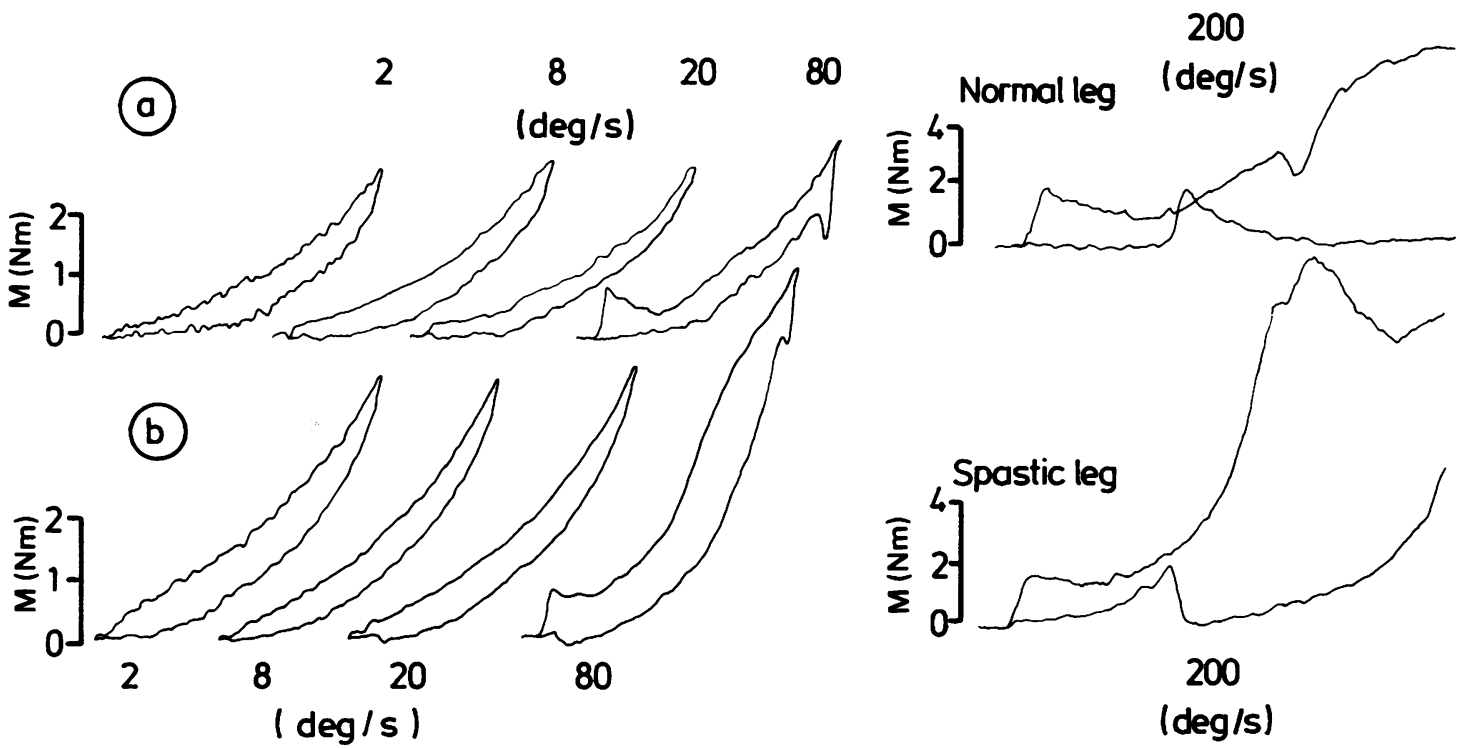

Fig 8 Length-tension curves of a patient with spastic hemiparesis. (a) unaffected leg, (b) spastic leg.

In nine patients, the amplitude of the shoulder $\left(\mathrm{M}_{\mathrm{s}}\right)$ emerging on the tension curve at prolonged resting periods between stretch cycles was assessed. The end-to-onset interval between stretch cycles was set to $10 \mathrm{~s}$, angular velocity was $20 \%$ s. There was significant increase $(p<0.05)$ of $M_{s}$ in relation to the duration of spastic symptoms (fig $9 \mathrm{E}$ ).

\section{Discussion}

Muscle tone at rest and during slow passive movements is exclusively due to intrinsic muscular properties. There is no electromyographic evidence that it is sustained by continuous motor neuron activity. This is also true in spastic patients ${ }^{13}$ and is confirmed by the results presented here. If our findings of increased plastic resistance in spastic muscle were due to tonic innervation, this would have been such a regular feature that it would have, on average, shown up in our EMG recordings.

Fluctuating levels of voluntary motor activity or shortening reactions of the tibialis anterior, when present, produced gross deformations in the lengthtension curves, in contrast to the highly reproducible L-T-curves of passive responses demonstrated in fig 1 . Tonic stretch reflexes, as observed in decerebrate cats, ${ }^{14}$ were not found in any of our spastic patients, and would have been abolished by ischaemic blocking of Ia afferents (fig 7). We therefore believe that there is convincing evidence that 
(a)

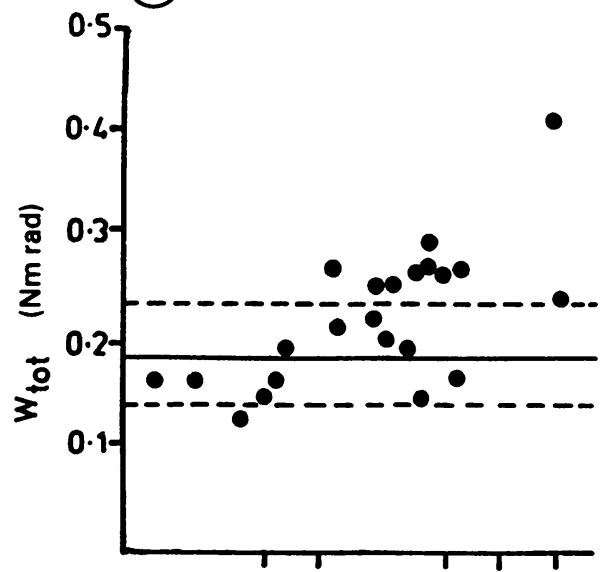

(c)
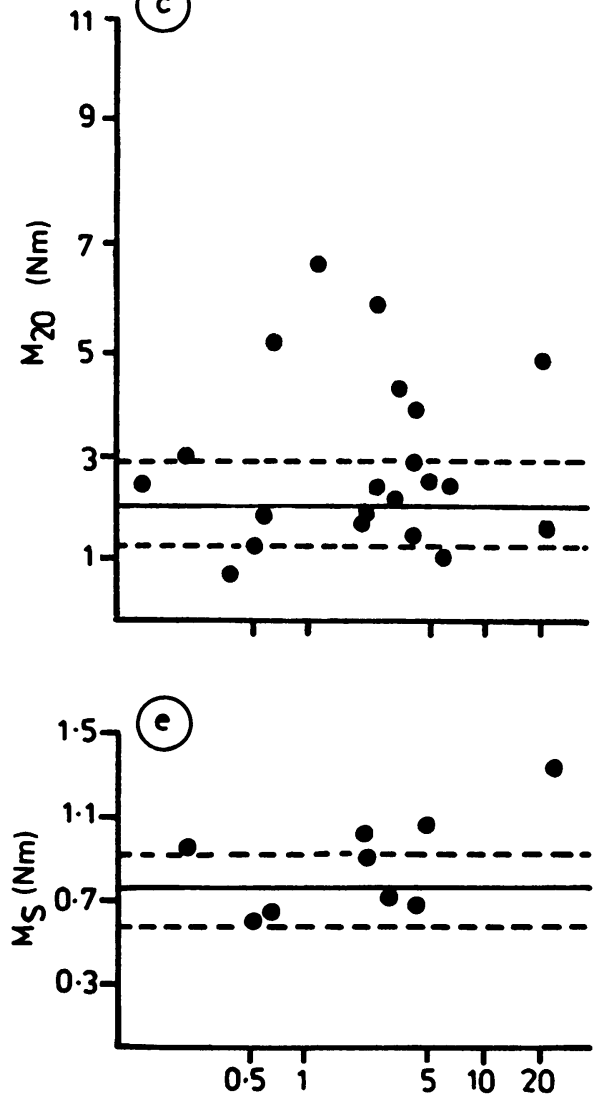

(b)
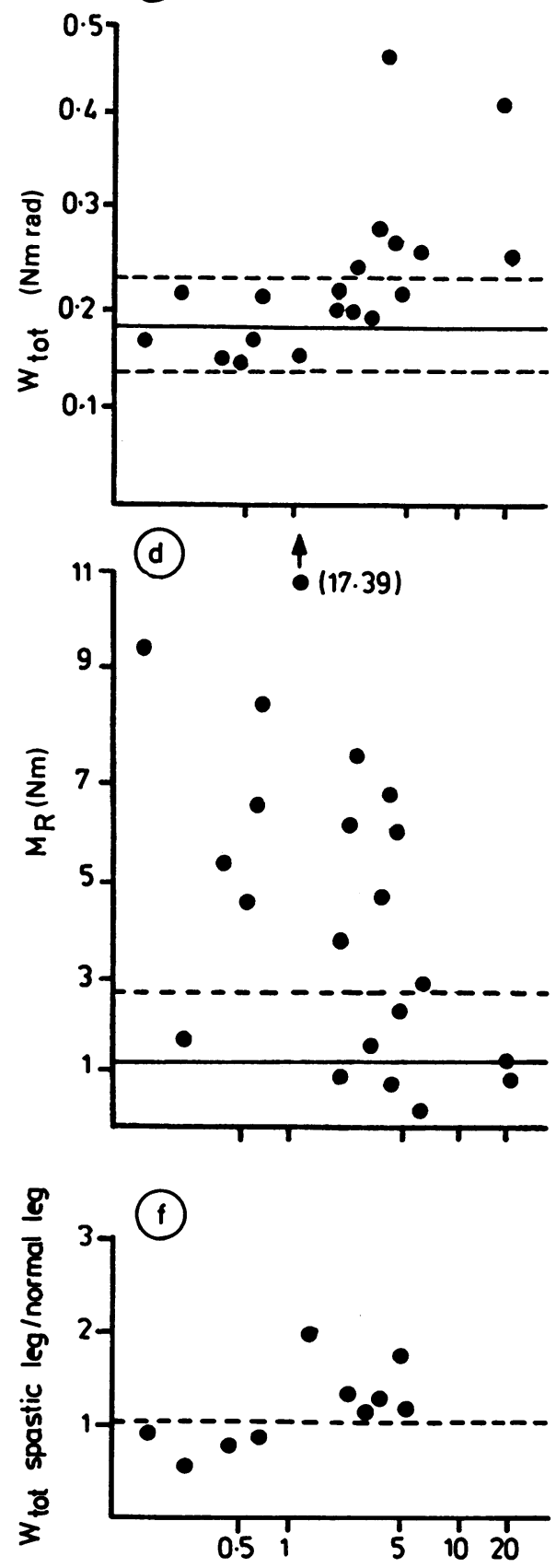

Duration of illness (years)

Fig 9 Relation between the duration of spastic symptoms and $W_{\text {tot }}$ at $2 \% s(a), W_{\text {to }}$ at $20 \% s(b), M_{20}(c)$, $M_{R}(d), M_{S}(e)$ and the quotient $W_{\text {ot }}(2 \%$ s) spastic/unaffected leg in 10 patients with spastic hemiparesis $(f)$. Mean (straight line) and SD (dotted lines) of control group (a-e). Mechanical muscle parameters $\left(W_{\text {to }}, M_{20} M_{S}\right)$ are abnormal only in patients with long-standing spastic illness (>1 year). Reflex amplitude $\left(M_{R}\right)$ is increased also in recent onset spasticity $(d)$. There is a significant correlation between $M_{S}$ and the duration of illness $(r=0.593, p<0.05$, regression line not plotted). 


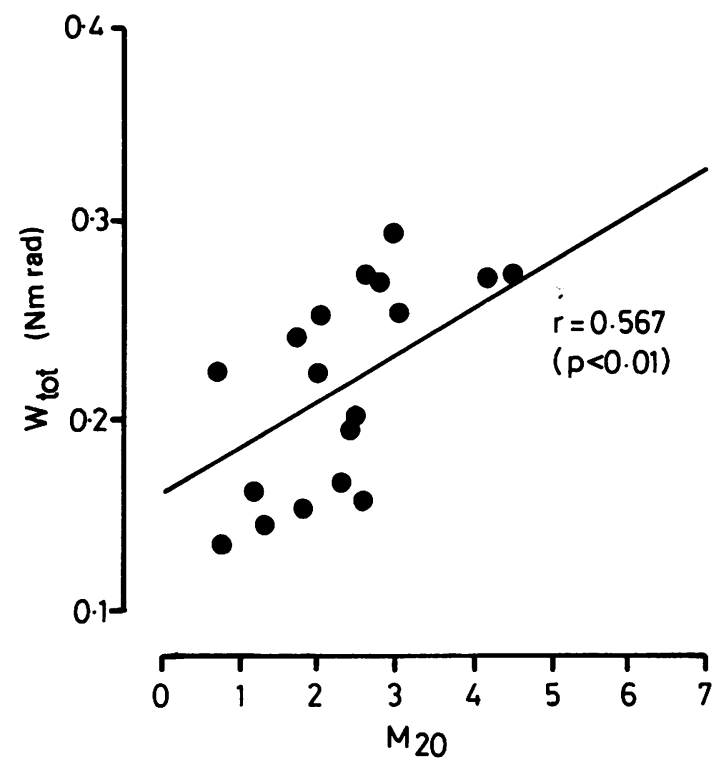

Fig 10 Work absorption $\left(W_{\text {tot }}\right.$ ) at $2 \%$ s plotted against the elastic momentum at $20^{\circ}$ dorsifiexion $\left(M_{20}\right) .21$ spastic patients. The correlation is significant and demonstrates that elastic and plastic resistance increase in parallel.

the phenomena observed in this study at slow rates of movement $\left(2^{\circ}, 8^{\circ}\right.$ and $\left.20^{\circ} / \mathrm{s}\right)$ originate from innate muscle properties.

In this study we observed a deformation of the length-tension curve similar to the one caused by the short range elastic component ${ }^{15-17}$ when the interval between two successive stretch cycles was longer than 1-2 s (fig 6A). According to Hill's theory, the height of the "shoulder" $\left(M_{s}\right)$ is related to the number of attached cross-bridges. For stretch beyond short range elasticity, mammalian and frog muscles exhibit a behaviour often described as viscous, because work is absorbed by the muscle when subjected to cycles of stretch and release. ${ }^{9121819}$ In contrast to other workers ${ }^{4} 18$ we found that the amount of work absorbed was not significantly related to angular velocity $\left(2^{\circ}\right.$ to $20 \%$ s). As viscosity is postively rate-dependent by definition, this finding demonstrates that at physiological rates of movement $(20 \% \mathrm{~s}$ corresponds to normal walking) human lower leg muscles exhibit no measurable degree of viscosity. This is also true in spastic patients. The resistance encountered in unexcited muscle beyond short range elasticity should therefore be termed "plastic". The discrepancy between our results and those of Rack and his co-workers ${ }^{19}$ may be explained by different experimental conditions. In their experiments muscles were stretched and released sinusoidally at high frequencies. At these rapid displacement velocities viscosity may prevail which would not be detectable by our methods. Plastic resistance, in contrast, may be negligible for small movement amplitudes if stretch is within short range elasticity and no cross-bridges are broken. The force responses to stretch observed by Fenn and Garvey ${ }^{18}$ were due to stretch reflex activity and therefore velocity-sensitive. Some velocity sensitivity was noted in resting muscles of spastic patients with severe contractures. ${ }^{3}$ None of our patients belonged to this group.

In some spastic patients, we found an increase of elastic as well as plastic resistance to slow passive ankle movements. Structural changes of the joint capsule could only explain alterations of elastic resistance; forcible disruption of connective tissue fibres of either muscle or joint capsule would produce an increased plastic stiffness only during the first stretch cycles. In our experiments these were discarded to exclude the effects of short range stiffness.

The relation of the changes of mechanical properties to the clinical phenomenon of contracture remains open to discussion. Two antagonistic effects may be considered:

(1) Stiffening or shortening of series elastic structures can be expected to enlarge the amount of stretch passed on to the sarcomeres, thereby increasing the plastic resistance.

(2) Increased stiffness of parallel elastic structures is likely to reduce plastic resistance by "protecting" the sarcomeres from being stretched at the cost of series elastic elements.

Our finding of an increased force response to sustained stretch $\left(\mathrm{M}_{20}\right)$ suggests in fact an increase of parallel elasticity, since under this condition the sarcomeres will yield to tension and allow the series elastic structures to relax. If effect (2) is predominant, it has to be combined with an alteration of passive properties of the contractile elements in order to explain the increase of plastic resistance found in our patients. This view is supported by the increase of the force momentum, $M_{s}$, at short range stiffness breakdown which indicates an alteration of crossbridge behaviour and cannot be explained by premature stretching of the sarcomeres due to shortening of series elastic elements. The delayed onset of these changes until about a year after the clinical manifestation of spasticity, and their independence of reflex behaviour support the hypothesis of a secondary structural alteration, such as a transformation from phasic to tonic type muscles. ${ }^{12}$ Further evidence has been provided by histochemical studies which revealed changes in enzyme patterns related to an altered oxidative metabolism in spastic 
muscle. ${ }^{20}$ Morphologically, an atrophy of type II fibres and, in long standing spasticity, hypertrophy of type I fibres, was seen. ${ }^{21}$ These changes are, however, unspecific and may also be encountered in Parkinsonism. In animal experiments, transformation from phasic to tonic type muscles (and vice versa) could be demonstrated by cross-reinnervation with motor nerves of the opposite type. ${ }^{22-24}$ Electrical stimulation of denervated muscles at frequencies typical of the firing rates of either slow or fast motor units produced similar results. ${ }^{25} 26$ This indicates that the stimulation rate, rather than axonal transport (which was interrupted in Lomo's experiments), is likely to be responsible for the transformation. Muscle properties altered by these procedures were twitch characteristics, such as twitch contraction time, half relaxation time, twitch-tetanus ratio, the fatigue index and enzyme patterns..$^{27-31}$ However, the passive mechanical properties were not assessed in these studies.

In spastic man, discharge rates of anterior horn cells are known to be abnormal. Inter-spike intervals are more irregular than those of normals. ${ }^{32}$ There is also indirect evidence that discharge frequencies on the whole are decreased. ${ }^{33}$ These abnormalities might cause a tonic transformation of spastic muscle similar to that in denervated muscles stimulated at low frequencies. In some of our patients with more than a year's history of spasticity, no evidence of muscular changes could be found. Some but not all of these had only a slight motor deficit. There are obviously other factors which determine the degree of muscular transformation. We were, however, not able to detect a difference between "spinal" and "cerebral" spasticity with our parameters.

In summary, our results suggest that spastic contracture is the result of complex process involving degenerative changes (atrophy, fibrosis) as well as an alteration of passive and probably also contractile properties of muscle. These may be regarded as an "out-of-control" functional adaptation. It is known that in slow muscles tetanic fusion is reached at lower stimulation rates than in fast muscles. It therefore follows that at decreased rates of motor neuron discharge, which were seen in association with spasticity, the force output of slow relative to fast muscles is probably larger. A moderate degree of tonic transformation of lower leg muscles, together with an increase of spring-like properties is functionally superior to a flaccid paresis. This is illustrated by the deterioration of motor performance occasionally seen in patients starting on antispastic medication.

This work was supported by the Deutsche Forschungsgemeinschaft (SFB 70). K-H Mauritz is the recipient of a Heisenberg Fellowship from the Deutsche Forschungsgemeinschaft. Present address of K-H M: Rehabilitation Engineering Center, Cleveland Metropolitan General Hospital, 3395 Cranton Road, Cleveland, Ohio 44109. We are grateful to V Dietz, R Jung, J Noth and S Fellows for reviewing the manuscript and to Mrs I Schwaller for technical assistance.

\section{References}

' Dietz V, Quintern J, Berger W. Electrophysiological studies of gait in spasticity and rigidity. Brain $1981 ; 104: 431-49$.

${ }^{2}$ Dietz V, Berger W. Normal and impaired regulation of muscle stiffness in gait: a new hypothesis about muscle hypertonia. Exp Neuro 1983;79:680-7.

${ }^{3}$ Herman R. The myotatic reflex. Brain 1970;93:273312.

${ }^{4}$ Hufschmidt A. Mechanical Responses of Human Muscle to Slow Stretch in Normals and Spastic Patients. Pfüigers Arch 1982;394:R42.

${ }^{5}$ Magladery DP, McDougal DB, Stoll J. Electrophysiological studies of nerve and reflex activity in normal man. Johns Hopkins Hospital Bull 1950;86:291-312.

${ }^{6}$ Schenck E, Bayer H. Die Wirkung künstlicher Zirkulationsunterbrechung in der Peripherie auf Eigenreflexe beim Menschen. Dtsch $Z$ Nervenheilkunde 1951;165:90-108.

${ }^{7}$ Gottlieb GL, Agarwal GC, Jaeger RJ. Response to sudden torques about ankle in man: V. Effects of peripheral ischaemia. J Neurophysiol 1983;50:297312.

8 Jiminez-Pabòn E, Nelson RA. Quantitative measurements of muscle tone in cats. Neurology (Minneap) 1965; 15:1120-6.

${ }^{9}$ Rack PMH. The behaviour of mammalian muscle during sinusoidal stretching. J Physiol (London) 1966; 183: 1-14.

${ }^{10}$ Webster DP. Rigidity in extrapyramidal disease. $J$ Neurosurg 1966;24:299-307.

"Duggan TC, McLellan DL. Measurement of muscle tone: a method suitable for clinical use. Electroencephalogr Clin Neurophysiol 1973;35:654-8.

12 Flitney FW, Hirst DG. Filament sliding and energy absorbed by the cross-bridges in active muscle subjected to cyclical length changes. J Physiol (London) 1978b;276:467-9.

${ }^{13}$ Chokroverty S, Medina J. Electrophysiological study of hemiplegia. Arch Neurol 1978;35:360.

${ }_{14}$ Matthews PBC. The dependence of tension upon extension in the stretch reflex of the soleus muscle of the decerebrate cat. J Physiol (London) 1959;147:52146.

${ }^{15}$ Hill DK. Tension due to interaction between the sliding filaments in resting striated muscle. The effect of stimulation. J Physiol (London) 1968;199:637.

${ }^{16}$ Rack PMH, Westbury DR. The short range stiffness of active mammalian muscle and its effect on mechanical properties. J Physiol (London) 1974;240:331-50. 
${ }^{17}$ Flitney FW, Hirst DG. Cross-bridge detachment and sarcomere "give" during stretch of active frog's muscle. J Physiol (London) 1978a;276:449-56.

${ }^{18}$ Fenn WO, Garvey PH. The measurement of elasticity and viscosity of skeletal muscle in normal and pathological cases; a study of so-called "muscle tonus". J Clin Invest 1934;13:383-97.

14 Joyce GC, Rack PMH, Ross HF. The forces generated at the human elbow joint in response to imposed sinusoidal movements of the forearm. J Physiol (London) 1974;240:351-74.

${ }^{20}$ Ahlquist G, Landin S, Wroblewski R. Ultrastructure of skeletal muscle in patients with Parkinson's disease and upper motor lesions. Lab Invest 1975;32 (5): 673.

${ }^{21}$ Edström L. Selective changes in the size of red and white muscle fibres in upper motor neurone lesions and in Parkinsonism. J Neurol Sci 1970;11:537-50.

${ }^{22}$ Close R. Effects of cross-union of Motor Nerves to Fast and Slow Skeletal Muscles. Nature 1965;206:831-2.

${ }^{23}$ Close R. Dynamic properties of fast and slow skeletal muscles of the rat after nerve cross-union. J Physiol (London) 1969;204:331-46.

${ }^{24}$ Luff AR. Dynamic properties of fast and slow skeletal muscles in the cat and rat following crossreinnervation. J Physiol (London) 1975;248:83-96.

${ }^{25}$ Lømo T, Westgaard RH. Contractile properties of muscle: control by pattern of muscle activity in the rat. Proc $R$ Soc (London) 1974; 187:99-103.

${ }^{26}$ Lømo T, Westgaard RH, Engebretsen L. Different stimulation patterns affect contractile properties of denervated rat soleus muscles. In: Plasticity of muscle. Pette D, ed. Berlin-New York: de Gruyter, 1980;297-309.

${ }^{27}$ Pette D, Smith ME, Staudte HW, Urbova G. Effects of long-term electrical stimulation on some contractile and metabolic characteristics of fast rabbit muscles. Pfü̈gers Arch 1973;338:257-72.

${ }^{28}$ Pette D, Müller W, Leisner E, Urbova G. Time dependent effects on contractile properties, fibre population, myosin light chains and enzymes of energy metabolism in intermittently and continuously stimulated fast twitch muscles of the rabbit. Pftuigers Arch 1976;364: 103-12.

${ }^{24}$ Salmons S, Sreter FA. Significance of impulse activity in the transformation of skeletal muscle type. Nature 1976;263:30-34

${ }^{30}$ Pette D, Tyler KR. Quantitatives changes in oxidative enzyme activity during chronic stimulation of rabbit fast muscle. J Physiol (London) 1981;317:22p.

${ }^{31}$ Mortimer J. Motor prostheses. In: Brooks VB, ed. Handbook of Physiology. Bethesda, 1981; vol. 2, section 1, 174-184.

${ }^{32}$ Freund HJ, Dietz V, Wita CW, Kapp H. Discharge characteristics of single motor units in normal subjects and patients with supraspinal motor disturbances. In: Desmedt J, ed. New Developments in EMG and clinical Neurophysiology. Basel: Karger, 1973;242-50.

${ }^{33}$ Tang A, Rymer WZ. Abnormal force-EMG relations in paretic limbs of hemiparetic human subjects. J Neurol, Neurosurg, Psychiatry 1981;44:690-8. 